\author{
Journal of NELTA Gandaki (JoNG) \\ (A peer reviewed Open Access Research Journal) \\ ISSN: 2676-1041 [Print] E-ISSN 2822-1559 [Online] \\ Vol. IV Issue (1-2) November, 2021, pp.83-97 \\ eJournal site: www.nelta.org.np/page/gandaki
}

\title{
Students' Perceptions of Pedagogical Change during the COVID-19 Crisis
}

Yam Nath Adhikari

Article History:

Submitted 17 June, 2021

Reviewed 25 September 2021

Accepted 30 October 2021

Corresponding Author:

Yam Nath Adhikari

Email:

adhikariyamnath421@gmail.com

Article DOI:

https://doi.org/10.3126/jong.v4i1-2.42646

Copyright information:

Copyright 2021 Author/s and Nepal English Language Teachers' Association, Gandaki Province

This work is licensed under a Creative Commons Attribution- Non

Commercial

4.0 International License

\section{(c) $(\$$}

Publisher

Nepal English Language Teachers'

Association Gandaki Province, Pokhara, Nepal

Email: neltagandaki2018@gmail.com URL.:www.nelta.org.np/page/gandaki

\section{Abstract}

Pedagogical change during the spread of Novel Corona Virus (COVID-19) crisis in Nepalese academia is being the matter of discussion and many academic institutions claim that they are adopting new pedagogy in their curricular activities during COVID-19 crisis. This study aims to find out the secondary students 'experiences of pedagogical change in language teaching and learning procedure. This paper explores an analysis of how pedagogical change enabled secondary students' experience of online pedagogy during the COVID-19 crisis to plan and manage their learning procedure. As a qualitative research, it employs internet-based semi-structured interview to investigate participants' experience of pedagogical change and the ground reality of online pedagogy in Nepalese Academic institution during pandemic situation of COVID-19. This paper also shows that how the pandemic situation affects the learning procedure of the students especially in rural Nepal. Online pedagogy is observed as an alternative mode of education in urban areas where there is minimum ICT infrastructure and a means to widen digital divide in rural areas. The students struggle with limited access to digital technology to manage their online learning and the low level of organizational support cannot help them to continue their learning in the pandemic situation. To support the students in their online learning, formulation and operation of policy in wide-ranging systems need to be developed in practice level to provide skills and facilities of ICT for effective distribution of online pedagogy throughout the nation.

Keywords: collaborative, ICT, interactive, digital divide, pedagogy, rural Nepal 


\section{Introduction}

The concept of online pedagogy was introduced from the correspondence courses that initiated at first in England in the mid-19 ${ }^{\text {th }}$ century (Kumar et al., 2017) with the help of computer networking and conferencing, the speedy growth of internet facilities employed its prominent space with creative development of online pedagogy. Moreover, the increasing access to internet facilities has promoted online mode of pedagogy across the world predominantly in developed countries with the beginning of $21^{\text {st }}$ century (Harasim, 1996). Allen and Seaman (2006) earlier reported that online pedagogy was adopted in mainstream education in 2003 and 2004 rapidly in the United States with the implementation of quality and extent of online pedagogy. The European Commission (EC) launched online pedagogy in 1990s with the development of internet and World Wide Web (WWW) to encourage open education in Europe (Dos Santos et al., 2016). Online pedagogy has become more flexible and technologically, economically and operationally feasible to disseminate education to the students of all levels. For example, online pedagogy with the rapid development of ICT has been extensively adopted in China (Liu, 2009). The use of internet facilities in teaching and learning can be traced with the implementation of National Curriculum Framework for School Education 2005 (Ministry of Education\& Sports, 2005). Although internet was developed in Nepal in 1993, its practice in education was quite low in the first two decades (Rana et al., 2018). Online pedagogy is considered as an important fact in this age of technology. In this face of a pandemic situation, all governmental academic institutions are imposing the same discipline as imposed by the entrepreneurial education system. In the developing country like Nepal, when school children are exposed to the internet, there is a real danger of the technology hindering their creativity. Moreover, schools in Nepal impose the new pedagogies of teaching indiscriminately, without so much as considering whether Montessori or primary level children are fit to be exposed to the technology, we must ask whether the sudden enthusiasm is driven by pedagogical imperative or financial interests. If we acknowledge that urban centers like Kathmandu and the corporate schools of developed cities cannot represent the entire educational situation of the country. The majority of which comprises government schools with little resources especially in the rural Nepal is not enjoying the pedagogical change during COVID-19 pandemic, we must ask ourselves what the consequences of our obsession with this changed pedagogy will be. If the majority of students without access to computers and the internet are going to feel left out, there is a real danger of students facing psychological pressure to continue their academic activities during the crisis. The pandemic spread of COVID-19 has created fear, anxiety and several concerns among the people around the world. It has disrupted every aspect of human life including education throughout the world (Bao, 2020). The pace of its spread made educational institution closure as one of the best preventive measure against it. COVID-19 crisis has created the largest disruption of education systems in history.

The Closures of schools and other learning spaces have greater impact were being used to alter and advance elevated education in the world, there is a threat that COVID-19 will threaten the segment, with severe penalty (Bhatraju et al., 2020). Technology based teaching especially online pedagogy has become complementary to keep educational activities functional in many parts of the world during the different types of crisis happened in the field of education The educational institutions in countries which were 
technologically advanced like UK, Japan, USA, Turkey etc. promote their technological competencies and adopt online pedagogy to develop the learners competency in using advanced technology in education (Kumar et al., 2017). But the countries which are technologically poor like Nepal have initiated online pedagogy and it has become as the force to continue teaching learning activities where there has no access of internet, online pedagogy. Educational institutions in each level have started online pedagogy during COVID-19 crisis whereas it is not found effective in the context of Nepal where there lacks the minimum ICT infrastructures to adopt online pedagogy.

The researches on online pedagogy show that students displayed a wide range of responses, with most expressing anxiety toward online pedagogy, disappointment regarding graduation ceremony, and online learning being different than standard in-class learning. Palvia et al. (2018) stated that online learning is partially or entirely internet based learning which requires both teachers and learners having technological knowledge and skills. The unpredictable spread of COVID-19 cases in the countries, schools and universities in Nepal have been closed and online pedagogy is forced to all the students from school to university level in Nepal without the development of minimum infrastructures of online pedagogy how it can be effective in the country like Nepal.

Based on the fact about the secondary students' perceptions and the ground reality of pedagogical change during the COVID-19 crisis. The researcher tries to find out what do secondary students experience of pedagogical change during the COVID-19 crisis in their learning procedure and how they are integrating themselves with the new learning system? The researcher conducted the research and found this online pedagogy as complementary to conventional physical classroom teaching during COVID-19 pandemic in Nepalese academia. Dawadi et al. (2020) conceded that only few particularly private schools and colleges in cities and towns where they have internet facilities have attempted to adopt internet-based pedagogy and learning to regulate their educational activities. The pedagogical change during the crisis compelled Nepalese students to adopt newer technology to manage their learning but the inadequate facilities of technology in the country could not support the students to continue their study effectively especially for those students who represent from the remote part of the country.

\section{Review of Literature}

For this research article, I have reviewed theoretical literature based on three interrelated strands: pedagogical approach, instructional models and assessment that are applied in the teaching learning process during COVID-19 crisis.

\section{Pedagogical Approach}

COVID-19 pandemic caused the closure of educational institutions, which has unprecedently created a situation for remote learning, normally internet-based. In this regard, developed nations are at an advantage as they have well-established minimum resources to adopt internet-based remote learning. To aid teachers and students in remote learning, an excess of advice is offered from all corners of the world to support for educational progress, mostly from stakeholders of the developed nations, with a focus on tools and materials that could be used to replace the conventional face-to-face class. Much of 
this advice focuses on the tool-based pedagogy for using available digital tools to ensure the continuation of teaching and learning activities on virtual mode. Where as in the context of Nepal, schools leaders, teachers, parents and students made self- learning of ICT use which worked as coping mechanism for the practitioners to promote learning strategies during the COVID-19 Crisis (Subedi and Subedi, 2020). John et al. (2021) found that majority of teachers varied their instruction, following best teaching practices, and had practice questions, quizzes and tests, independent and collaborative projects, reading, discussion, and even watching short instructional videos. Teachers' and students' interaction on online learning is found one of the best pedagogical procedures which played an important role to enhance the learning performance of the learners (Paudel, 2021). It appears that synchronous instruction was a significant component of online teaching. As these short-term temporary solutions are pedagogically, socially, politically, and economically necessary, we could not be forgetful of the fact that tools are to facilitate the process of learning and not to replace it (Teras et al., 2020). Therefore, the researcher argues that the right approach of learning in this crisis period is process-based pedagogy with the emphasis on how learners will access the teaching and learning materials safely and reliably and use those in their learning with some sense of engagement as in face-to-face with friends and teachers.

The idea of instant dealing of the eminent threat echoes with the concept of crisis management where an organization focuses on a process to deal with the unexpected and troublesome events that challenge the very existence of a company and threats to harm the stakeholders. Like a company, educational institutions are also faced with the challenges that the COVID-19 has put forth by disrupting the conveyor belt of an educational process, and among their stakeholders, students are largely affected. Among various strategies of crisis management, process orientated crisis management is more applicable to deal with the present crisis. The process-oriented strategy is more focused on how crisis impacts an organization and the task needed to carry out to minimize the effect of the impact (Selwyn \& Jandric, 2020). By comparing a business organization with an educational institution one can recognize the present COVID-19 pandemic as a crisis event, disruption of the education as an impact of that event, and continuation of education. In this study, the term crisis pedagogy is used to illustrate the emergency remote learning and teaching task that occurred to minimize the impact of the pandemic event while educational institutes are on forced shutdown and social distancing measures are in practice. Therefore, in the context of the present study, crisis pedagogy should be understood as crisis-aware teaching that involves design, develop, and delivery of teaching and learning activities and related assessments to better support students as they navigate through these uncertain times.

\section{Instructional Models}

Like thousands of teachers all over the world, the present author also faced the challenge of an unexpected and urgent request of changing from face-to-face classes to online and distance learning from home as lockdowns and restriction began in Nepal face-to-face mode shifted to the online during COVID-19 crisis. As Pun (2013) stated that the remarkable development of newer technologies provide so many options as it encouraged the teachers and students to make their teaching and learning collaborative, 
cooperative, supportive, interesting and productive when students and teachers get the opportunity of using newer technology in their pedagogical process. The crisis pedagogy during COVID-19 pandemic emerged as a reasonable solution to deal with this unique challenge; the teaching model adopted to deal with this challenge of crisis, following the two basic components: self-paced asynchronous learning and facultyguided synchronous learning. The aim of the asynchronous learning was to provide all the learning and teaching materials such as power-point slides, companion readings, and some exercises to the students so that they could access all those learning materials remotely and safely from their home. Therefore, all teaching and learning materials were offloaded in the Learning Management System (LMS). It is well known that the LMS is key to administer web-based learning activities (El-Mowafy et al., 2020). The offloaded content in Canvas provided mobility to students' learning by enabling them to have safe and reliable access to learning resources at their own pace and comfort and with various devices (Canvas platform is compatible with many devices). The first purpose of the crisis pedagogy was thus achieved by allowing the student to have safe and reliable access to teaching and learning materials. Recently, a similar approach of teaching by combining an asynchronous and synchronous method was reported to be effective in content delivery, active learning, and student engagement during the COVID-19 pandemic (Sunasee, 2020). The second aim of the crisis pedagogy of engaging students in the learning process by establishing some sense of learner's community was achieved through Zoom-based live synchronous sessions which proved to be very useful in mimicking real-time face-to-face learning experience.

Zoom-based synchronous lecture sessions were adopted, with the focus of utilizing live-class time for meaningful learning to encourage students to be more active participant which in turn will facilitate their needs for autonomy and competence as pointed out by self-determination theory (Harris et al., 2017). These live sessions were utilized not only to reinforce important concepts, but open discussions were also carried out on various aspects of students' learning during the crisis and encouraged the students to share their experience, how they were dealing with the crisis. Students were also encouraged to share and discuss issues and problems among themselves and in a group during the live sessions. Students were encouraged to turn their video on during the live session so that they have some sense of community and belonging. These are essential, particularly, in this hard time as students do not have an opportunity to meet in person. On the other hand, students were less keen to keep their video on in a live Zoom lecture session. The possible reasons could be that the circumstances in which students were in synchronous learning were not so conducive because of the third-person presence in the home or feeling of not properly dressed for the live sessions or behavioral preference. Nonetheless, the students' who got the chance to engage in the live session was good. Shrestha et al. (2021) stated that during COVID-19 crisis the students connect themselves in their learning process using Facebook, Zoom, and Google Meet, email Messenger groups, WhatsApp, Viber and phone calls. The Messenger groups were found one of the most popular means of communication among the students and teachers. similarly, Sharma et al. (2021) found that Chat as the best interaction procedures for teachers and students in their remote teaching and learning which was used in a high range by teachers and students in the crisis and other commonly used instructional methods were PowerPoint slides, sharing documents, emailing and video conferences, the findings claim that both the 
synchronous and asynchronous means of distance learning were used in their new learning system during the COVID-19 pandemic.

\section{Assessments}

It is significant that in the sudden emergency pivot to the remote learning, assessment should not be pushed aside as they are still an important part of the course learning outcomes, and instead some changes in the assessment systems are required. Jankowski (2020) stated $97 \%$ of the educational institutes in the USA has made some changes in the assessment system in response to the COVID-19 crisis. Likewise, higher educational institutes in Australia made some form of change in their assessment process. The core features of teaching methods adopted during COVID-19 Pandemic are; teaching methods In-class, face-to-face and synchronous online, virtual, synchronous. (García-Peñalvo et al., 2021) stated that traditional face-to-face way of teaching and learning strategy has to be shifted to online mode of learning with no purposeful planning, the biggest challenge has been the online assessment of the learning process. Learning Activities \& Assessments Lectures, tutorials, assignments (group and individual) and final exam zoom lectures, online quizzes, tutorials, online assessments (individual), and online in-class activities. The tutorial sessions were still a part of the online sessions and were primarily used for assessment scaffolding and problem-solving. One of the major changes that were made in the assessment was the introduction of high-level thinking assessments instead of final exam. The new assessment has provided students an ample opportunity to demonstrate their learning through an alternate measure. Dawadi et al. (2020) found that calculation of teachers' grades in the classroom on the basis of the students' performance is one of the potential alternatives for the assessment of the students in the board examination which is also regarded as the reliable source for assessment. Means and Neisler (2021) reported that students were more satisfied when they were asked to reflect on their own learning experience on what they have learned and what they need to learn. One of the alternate assessments that were introduced as the meaningful and authenticable assessment practice.

\section{Methodology}

This study adopts qualitative research and collected the data from the respondents through internet based semi-structured interviews among the participants (Cohen et al. 2013). Sixteen students of four secondary schools (four from each school) were purposively selected to explore their perception and 
experiences of Pedagogical Change during the COVID-19 Crisis and were approached through personal contact for the interview. Some of them were also determined by the referral of the teachers. After obtaining the informed consent from the participants, they were interviewed on multiple occasions up to data requirement. Interviews were recorded in my personal recording device and later stored in the laptop. Various archived documents were read before gathering data for interpreting the ground reality of the phenomenon and to ease on analysis of interviews.

Before collecting data, participants were followed on their phone and Facebook Messenger which helped building a rapport with them. The interview records were transcribed, then organised thematically into the specific themes and interpreted using interpretive phenomenological analysis (IPA), based on Smith and Shinebourne (2012). The data gathered through interviews with students provided the ground reality on Students' Perceptions of Pedagogical Change during the COVID-19 Crisis. All the participants are renamed with pseudonyms to maintain anonymity.

\section{Results}

The researcher developed three themes from the data which were obtained through the interview with the respondents and were analysed using interpretative approach that has included the findings related to the Secondary school students' perceptions and experiences on pedagogical change during COVID-19 crisis.

\section{Development of learning opportunities}

The majority of the participants in our interview opined that the pedagogical change during COVID-19 crisis has promoted the learning opportunities even in the rural Nepal, the students get the chance of learning opportunities in the time of COVID-19 closure. Language learning has been found as motivating and interesting in the classroom using various ICT tools during the crisis. New learning system makes teaching and learning activities more productive. It has created better learning opportunities to develop learning performance among the students even in rural Nepal also. For instance, Pratik at Prabhat secondary school, said:

In my opinion, the pedagogical change in the time of crisis supports the students to continue teaching and learning activities using various ICT tools which help the students to continue academic activities and the new learning system promote students' learning skills in the new trend.

The argument revealed that how online pedagogy helps to continue teaching and learning in Nepal, it also helps meet the learning objectives of their courses during the COVID-19 pandemic. The students get the chance to learn new models of various learning styles which helps the learners to cope with the new technology in the language learning. The students argued that they can search learning materials using various freely available ICT tools like Google and You Tube with the help of internet which make their lesson simple to understand. Majority of the participants said that use of ICT tools arouses the interest towards the lesson and students are found motivated in the language learning process.

In addition, pedagogical change during the crisis of COVID-19 makes the students' learning meaningful interactive and productive. It is also being fruitful for lessening the teachers' talk time in the 
classroom and to make the learning achievement better. This type of pedagogy has promoted collaborative learning among the students. Kabita, a student at Kalyan secondary school, shares the similar type of experiences of pedagogical change in English language learning as she expressed:

Online pedagogy in language learning advances the students' motivation and involvement towards language learning and supports to comprehend the text easily. Use of technology in learning procedure helps to develop the students' learning skills by interacting with our friends, seniors and teachers.

It was clear from our interview that online teaching and learning would be beneficial for many students who are not interactive because technology motivates learners to take part in interactive language learning process. They are also found supportive to each other in the process of language learning. Here Jagriti, from Joti secondary school expressed her opinion about the technology-friendly language class:

With the help of technology in online learning many students can have their open and distance learning in their free time and makes their learning easy. The students can get the opportunity of quality education from various part of the country if the schools are equipped with ICT.

It showed a clearer picture of how students can get a learning opportunity by using new technologies in language teaching and learning and gradually take advantage of new system of learning initiated by the academic institutions in the process of initiating new system of language learning during the pandemic situation of COVID-19. Not only had that use of technology also provided access to internet facilities that would promote distance and online learning. Chang of pedagogy gradually ensures opportunities for language learners to achieve equal quality education even in remote areas of the country. Technology in education has found as a supportive tool to interact and develop learning opportunities of various learners from home and abroad to know the new ways of learning.

\section{Enhancing Collaborative Learning}

The majority of the participants in their interviews expressed that the change of pedagogy has supported the practitioners to promote the learner-friendly environment in the academic institutions and advances the students' involvement in classroom activities. In our interviews with students focused on the use of various ICT tools to bring newness in the pedagogical process. The new learning pedagogy requires integration of technology which stimulates the motivation towards the lesson. The participants expressed that their teaching and learning becomes meaningful and supportive when both teachers and students could use newer technology in the language classroom. For example, Pralav at Pragati secondary school said:

This type of change in curricular activities develops the cooperation among the teachers and students to solve their difficulties in developing different learning skills among them and it helps both the teachers and students to make their teaching learning activities meaningful.

The argument clearly indicated that how students developed their knowledge of ICT tools and skills to organize and manage their teaching and learning activities effective with the help of online pedagogy during the COVID-19 crisis in the context of rural Nepal also. The participants argued that the new system of learning supports the learners to engage distance learning and learn cooperating with their friends and 
the teachers to continue their learning sharing different learning materials using various freely available ICT tools like Zoom, Google Meet, YouTube and Facebook messenger which enhance the learner-friendly environment to develop the students' involvement in learning during the COVID-19 crisis.

With the help of technology in a language classroom, the teachers can show various teaching-learning materials through Google and YouTube which makes the language teaching interesting for both students and teachers. Prapti from the same school shared her same kind of experience about the pedagogical change in their language learning, for example,

Learning will be interesting and effective when the technology is used in our learning process. Students can have self-learning and we can get the chance to share in our subject matter to make our learning meaningful. The new learning system also encourage us to integrate with technology which leads our teaching to the modern learning process.

The expression reflected how both teachers and students developed their knowledge of ICT tools and skills to organise and manage their teaching and learning activities. Students in our interviews appreciated the use of technology in online learning where the students can get an opportunity to develop self-learning by searching teaching and learning materials with or without the help of their teachers. Bhim, at Bhawani secondary school, shared his similar type of experiences during his online learning, this type of pedagogical change helps them to integrate with technology in their new learning system in the crisis, for example,

Change of pedagogy in our learning brings variety of the materials to make the lesson understandable even in the absence of the teacher. This type of learning promote cooperation, collaboration and sharing among the students and makes the learning student-center.

It was clear that the change in pedagogy during the pandemic situation assists the students' learning process and it makes students' learning long-lasting. The proper use of technology in teaching helps both teachers and students to search for supportive materials to make their lesson meaningful and interactive in online mode. Moreover, the participants in their interviews said that technology has been as source materials to avoid confusions related to teaching and learning for both teachers and students.

\section{Challenges in Managing Resources}

Interviews with the participants revealed that they faced the problems of technology in their new system of teaching and learning activities. In particular, students from rural areas frequently experienced interruption of internet connection and sound in online classes. The poor connectivity of internet, unstable electricity and limited ICT skills of both teachers and students were observed the major problems in virtual learning. However, online pedagogy facilitated teachers and students to break the paucity of educational systems and continue educational activities at the schools during COVID-19 pandemic. For instance, Subina, at Sunflower, said:

There is no proper facility of internet for online learning in the remote part of the country ours. When we talk about city area, there is no problem. Those who are especially living in rural areas are struggling for online classes because of poor ICT infrastructures as well as unstable electricity. Her comment provided a picture of how a large number students living in remote areas have been 
struggling to access online education. It also indicated that millions of students in remote villages who have no smart devices or computer and where there is no internet access may not know about such pedagogy. It will widen the digital divide between rural and urban. She further said in our interview that there were many other students like her who were unable to manage essential ICT tools and devices for their online education because they were struggling for food rather than their education in the COVID-19 crisis. The majority of participants shared that they struggled to manage mobile data, the only option in their remote villages of the country where they are living, for their online learning which was not reliable. Similarly, Mina, a student at the same school, expressed:

Our school started online classes through Zoom App from the second month of lockdown. Before that, it provided orientation related to it. Unfortunately, I did not get the notice about it and felt difficulty to join in it. Online teaching is not so effective for those who are unable to manage the necessary technology needed for online pedagogy.

Her voice echoed that although many academic institutions were conducting online classes through various ICT tools, students experienced difficulties in managing them due to inadequate knowledge about digitally supported learning. However, they were able to manage themselves by gradually developing skills for their new learning system in the following days. Mina's expression reflected that limited skills of technology, lack of digital devices and the poor bandwidth of internet especially in remote part of the country raised the question about the effectiveness of online pedagogy in the country. In contrast to her idea, Madhu, at Marigold School, Said:

Online learning is much more suitable and effective in the context of Nepal because we need to spend more time to reach or we have to leave our homes for higher education. Online pedagogy can be an alternative to existing education system and supports students, teachers and academic institutions to extend teaching and learning activities.

His expression reflected that online pedagogy in COVID-19 crisis has supported students living in remote part of the country. He appreciated online pedagogy, a new mode of teaching and learning emerged in this pandemic, that this new practice can be made sustainable for the future as an alternative to the existing traditional mode of face-to-face learning system. It was much clearer from his idea that many students who cannot afford on-school education particularly based on cities can continue their higher education from their home without being physically present in the physical classes. Further conversation with him indicated that the innovative learning system has brought newer approaches to strengthen learning abilities of students with the help of various ICT tools. It has supported the students in building knowledge and making themselves proficient to achieve the opportunities of education. Although the majority of participants reported complexities such as inadequate policy of academic institutions about the online pedagogy, lack of ICT infrastructures in rural areas and people's lack of affordability, some students living in urban areas appreciated the online teaching and learning initiated with the rise of COVID-19 and following lockdown in the country. However, the majority of the students shared their experiences of online learning that online pedagogy could not be as effective as physical classes. Shuvani, at Sunflower School, expressed: 
We cannot develop social intimacy through online classes which we can from in-person contacts in schools.

It was much clearer from her expression that although online pedagogy can be feasible and costeffective in the context of Nepal where there are millions of students after school cannot migrate to cities or towns for higher education, in absence of physical presence of both students and teachers, they may not be able to develop social skills through online communication and independent learning from home. Her comment revealed that physical proximity has great importance in teaching and learning which cannot be fulfilled by online mode of learning. Her expression reflected how students' frustration increases higher when they have less chance of face-to-face interaction in their online learning system. Moreover, it is also indicated that students who have to independently work on their own have limited time to discuss learning issues with their teachers and colleagues and cannot talk to each other whenever they like. Interviews with the participants identified that the schools were unable to impart online pedagogy to all the students and that they could not manage proper evaluation system through online mode.

\section{Discussion}

Findings suggested that a large number of students from remote areas were unable to access new pedagogy during COVID-19 pandemic, due to lack of proper planning, training and preparation. In absence of minimum ICT infrastructure, internet connectivity and students' knowledge and skills of ICT (Rana et al., 2019) that required for online learning, the students living in remote villages were unable to access online pedagogy during the pandemic situation. Many studies Dhawan (2020), Huang et al. (2020) and Rajhansb et al. (2020) have reported that COVID-19 has become an opportunity for many international schools and universities to shift their pedagogical practices from conventional physical classroom to online interactive pedagogy, the limited practices of online pedagogy in different academic institutions provide a picture of how secondary school students have struggled to shift from their conventional physical learning to online learning initiate with limited resources, low level online and distance education knowledge and weak administrative preparation and forcefully regulated their low level of practices. Similar to the findings of Dorn et al. (2020), this study has found that during COVID-19 pandemic, online pedagogy was abruptly adopted to complement academic vacuum that occurred after the closure of academic institutions. However, for those who could access online education, a quick shift towards innovative technology has provided the chance for teachers and students to advance academic engagement. It, to some extent, resonates with the findings of Bangert (2008) that effective online teaching is based on creating and delivering of quality web-based courses. Despite limited participation of students, increased interaction, goal-orientation and fulfilment of immediate academic need were the common benefits found in the study. These benefits, however, conquer the problem experienced during the management of online class access and delivery. The challenges found during the study were, for instance, poor bandwidth of internet, unreliable electricity, low affordability of internet tariff, insufficient technological resources, and limited ICT skills of teachers and students. This finding to some extent concur with the earlier study of Rana et al. (2018). The persistence of these obstacles for adopting pedagogy change in rural Nepal is likely to create wider gap of digital 
divide among Nepali students. Conventional face-to-face mode of education could not exist in the period of COVID-19 pandemic and it is shifted to online teaching by the schools to complement the existing education system in Nepal.

In addition, findings of this study suggest the sudden pedagogical change in the pandemic have tried to fill the academic vacuum even with the limited technological resources in Nepali academic institutions. This study indicated that online pedagogy has provided teachers and students with opportunities for equipping with the technology and new pedagogical knowledge and skills. A large number of students from rural Nepal expressed their struggle to join in their online classes due to their inadequate knowledge of ICT and limited or no access to ICT. It concurs with the study of (Bao, 2020) that insufficient knowledge of online teaching among the teachers in Chinese Universities created the problem for effective dissemination of online teaching and learning activities. Findings suggest that insufficient development of ICT resources has become barrier in effectively imparting online pedagogy for students especially in the public schools of Nepal. However, the initiatives of the schools in Nepal suggest that despite the limited ICT resources in and outside the schools premises particularly in rural areas, their attempts to implement online teaching and learning in the crisis of COVID-19 provide an idea of how they can survive with limited support from the government and sustain even in the hardest situation.

\section{Conclusion and Implications}

The change of pedagogy during COVID-19 pandemic has become an opportunity for teachers, students and academic institutions to adopt modern technology in their pedagogical practices but the lack of minimum facilities in Nepalese academic institutions especially in rural Nepal can't help students' to continue their learning opportunity effectively in the pandemic situation. However, the use of freely available ICT tools such as Zoom, Microsoft Teams, and Google Meet somehow enabled students to manage their learning from home and work collaboratively to complete regular curriculum. This change in the pedagogical process tries to complement the conventional face-to-face mode of learning in the crisis. However, secondary students expressed their concern about the difficulties of managing online resources for their learning because they had to struggle to manage ICT resources for their virtual learning. Students in urban areas to some extent got the benefits of this online pedagogy during the pandemic situation and appreciated the initiation of online teaching by their schools although a large number of students from rural areas struggled to manage basic ICT infrastructures for adopting this pedagogical change to continue their learning. Findings suggest that the schools in Nepal need to develop minimum ICT infrastructure, train teachers to enable them to use available ICT facilities and provide all the students an access to online education.

Lack of ICT infrastructures, poor internet access, insufficient training for teachers, electricity problems, students' low economic status and both students and teachers' limited ICT skills and knowledge have been identified major obstacles for the effective implementation of online pedagogy in the schools of Nepal. However, this study has identified potential of online pedagogy, although inadequate practice during the pandemic situation, in the context of Nepal which can be extended to future educational development. 
This study suggests both academic institutions and the government equipping schools, teachers, and students with minimum ICT infrastructures, knowledge and skills, systematically implement educational policies on ICT for the development of online pedagogy to equally reach all the students, and transform traditional pedagogies to online pedagogy effectively throughout the nation in the future.

\section{References}

Allen, I. E., \& Seaman, J. (2005). Growing by degrees: Online education in the United States, 2005. T. S. Consortium. https://files.eric.ed.gov/fulltext/ED530062.pdf

Bangert, A. W. (2008). The Development and Validation of the Student Evaluation of Online Teaching Effectiveness. Computers in the Schools,25(1-2),25-47.https://doi.org/10.1080/07380560802157717

Bao, W. (2020). COVID-19 and online teaching in higher education: A case study of Peking University. Human Behavior and Emerging Technologies2578-1863, 2(2), 113-115. https://doi.org/10.1002/ hbe2.191

Bhatraju, P. K., Ghassemieh, B. J., Nichols, M., Kim, R., Jerome, K. R., Nalla, A. K., Greninger, A. L., Pipavath, S., Wurfel, M. M., \& Evans, L. (2020). Covid-19 in critically ill patients in the Seattle region case series. New England Journal of Medicine, 382(21), 2012-2022.

Cohen, L., Manion, L., \& Morrison, K. (2013). Research methods in education. Routledge.

Dawadi, S., Giri, R., \& Simkhada, P. (2020). Impact of COVID-19 on the Education Sector in Nepal-Challenges and Coping Strategies. Sage Submissions, 1. https://doi.org/10.31124/ advance.12344336.v1

Dhawan, S. (2020). Online learning: A panacea in the time of COVID-19 crisis. Journal of Educational Technology Systems, 49(1), 5-22. https://doi.org/10.1177/0047239520934018

Dorn, E., Hancock, B., Sarakatsannis, J., \& Viruleg, E. (2020). COVID-19 and student learning in the United States: The hurt could last a lifetime. McKinsey \& Company.

Dos Santos, A. I., Punie, Y., \& Castaño-Muñoz, J. (2016). Opportunities and challenges for the future of MOOCs and open education in Europe. Books to MOOC, 81-91. https://portlandpress.com/ DocumentLibrary/Umbrella/Wenner\%20Gren/Vol\%2088/PPL_Wenner_Ch07.pdf

El-Mowafy, A., Kuhn, M., \& Snow, T. (2013). Blended learning in higher education: Current and future challenges in surveying education. Issues in Educational Research, 23(2), 132-150. https://doi. org/10.3316/ielapa.354446195879346

García-Peñalvo, F. J., Corell, A., Abella-García, V., \& Grande-de-Prado, M. (2021). Recommendations for Mandatory Online Assessment in Higher Education During the COVID-19 Pandemic. In Radical Solutions for Education in a Crisis Context (pp. 85-98). Springer. https://doi.org/10.1007/978-98115-7869-4_6

Harasim, L. (1996). Online Education: The Future. In T. M. H. Timothy D. Stephen, Timothy Stephen (Ed.), Computer networking and scholarly communication in the twenty-first-century university. (pp. 203-214). Suny Press.

Harris, M., Marti, J., Watt, H., Bhatti, Y., Macinko, J., \& Darzi, A. W. (2017). Explicit bias toward high- 
income-country research: a randomized, blinded, crossover experiment of English clinicians. Health Affairs, 36(11), 1997-2004. https://doi.org/10.1377/hlthaff.2017.0773

Huang, R., Tlili, A., Chang, T.-W., Zhang, X., Nascimbeni, F., \& Burgos, D. (2020). Disrupted classes, undisrupted learning during COVID-19 outbreak in China: Application of open educational practices and resources. Smart Learning Environments, 7(1), 19. https://doi.org/10.1186/s40561-020-00125-8

John Lemay, D., Doleck, T., \& Bazelais, P. (2021). Transition to online teaching during the COVID-19 pandemic. Interactive Learning Environments, 1-12. https://doi.org/10.1080/10494820.2021.1871 633

Kumar, A., Kumar, P., Palvia, S. C. J., \& Verma, S. (2017). Online education worldwide: Current status and emerging trends. Journal of Information Technology Case and Application Research, 19(1), 3-9. https://doi.org/10.1080/15228053.2017.1294867

Liu, M. (2009). The design of a web-based course for self-directed learning. Campus-Wide Information Systems, 26(2), 122-131. https://doi.org/10.1108/10650740910946846

Means, B., \& Neisler, J. (2021). Teaching and Learning in the Time of COVID: The Student Perspective. Online Learning, 25(1), 8-27.

Ministry of Education and Sports. (2005). National Curriculum Framework for School Education (Preprimary-12) in Nepal 2005. Curriculum Development Centre.

Palvia, S., Aeron, P., Gupta, P., Mahapatra, D., Parida, R., Rosner, R., \& Sindhi, S. (2018). Online education: Worldwide status, challenges, trends, and implications. Journal of Global Information Technology Management, 21(4), 233-241. https://doi.org/10.1080/1097198X.2018.1542262

Paudel, P. (2021). Online education: Benefits, challenges and strategies during and after COVID-19 in higher education. International Journal on Studies in Education, 3(2), 70-85. https://doi. org/10.46328/ijonse.32

Pun, M. (2013). The use of multimedia technology in English language teaching: A global perspective. International Journal of Interdisciplinary Studies, 1(1), 29-38. https://doi.org/https://doi. org/10.3126/ctbijis.v1i1.10466

Rajhans, V., Memon, U., Patil, V., \& Goyal, A. (2020). Impact of COVID-19 on academic activities and way forward in Indian optometry. MERLOT Journal of Online Learning and Teaching, 13(4), 216226. https://doi.org/10.1016/j.optom.2020.06.002

Rana, K., Greenwood, J., \& Fox-Turnbull, W. (2019). Implementation of Nepal's education policy in ICT: Examining current practice through an ecological model. The Electronic Journal of Information Systems in Developing Countries, 86(2), e12118. https://doi.org/10.1002/isd2.12118

Rana, K., Greenwood, J., Fox-Turnbull, W., \& Wise, S. (2018). A Shift from traditional Pedagogy in Nepali Rural Primary Schools? Rural teachers' Capacity to Reflect ICT Policy in Their Practice. International Journal of Education and Development using ICT, 14(3).

Selwyn, N., \& Jandrić, P. (2020). Postdigital Living in the Age of Covid-19: Unsettling What We See as Possible. Postdigital Science and Education, 2(3), 989-1005. https://doi.org/10.1007/s42438-02000166-9 
Sharma, M., Onta, M., Shrestha, S., Sharma, M. R., \& Bhattarai, T. (2021). The Pedagogical Shift During COVID-19 Pandemic: Emergency Remote Learning Practices in Nursing and its Effectiveness. Asian Journal of Distance Education, 16(1), 98-110.

Shrestha, S., Haque, S., Dawadi, S., \& Giri, R. A. (2021). Preparations for and practices of online education during the Covid-19 pandemic: A study of Bangladesh and Nepal. Education and Information Technologies. https://doi.org/10.1007/s10639-021-10659-0

Smith, J. A., \& Shinebourne, P. (2012). Interpretative phenomenological analysis. In APA handbook of research methods in psychology,2: Research designs: Quantitative, qualitative, neuropsychological, and biological. (pp. 73-82). American Psychological Association. https://doi.org/10.1037/13620005

Subedi, D. and Subedi, R. (2020). Practicing self-learning of ICT for resilience amidst the COVID-19 outbreak: Experiences from Kathmandu valley. Research in Educational Policy and Management, 2(2), 78-96. https://doi.org/10.46303/repam.2020.5

Yam Nath Adhikari is a Teaching Assistant at Prithvi Narayan Campus, Pokhara. He has worked as an EFL teacher for more than a decade. He has published numbers of articles in different journals and presented the papers in various national and international conferences. He is a life member of NELTA. His professional interests include teaching strategies used in ELT. 